Facile preparation of antibacterial, highly elastic silvered polyurethane nanofiber fabrics using silver carbamate and their dermal wound healing properties

Suk-Min Hong $^{1}$, Jong-Wan Kim ${ }^{1,2}$, Jonathan C Knowles ${ }^{1,3}$ and Myoung-Seon Gong ${ }^{1,2^{*}}$

${ }^{1}$ Department of Nanobiomedical Science and BK21 PLUS NBM Global Research Center, Dankook University Graduate School, Chungnam 31116, South Korea

${ }^{2}$ Institute of Tissue Regeneration Engineering, Dankook University, Chungnam 31116, South Korea

${ }^{3}$ Division of Biomaterials and Tissue Engineering, UCL Eastman Dental Institute, University College London, London, UK

*Corresponding author: Tel.: +82 41550 3431; fax: +82 550 9229. E-mail address: msgong@dankook.ac.kr (M.S. Gong). 


\title{
Facile preparation of antibacterial, highly elastic silvered polyurethane nanofiber fabrics using silver carbamate and their dermal wound healing properties
}

\begin{abstract}
In this study, polycarbonate diol/isosorbide-based antibacterial polyurethane (PU) nanofiber fabrics containing Ag nanoparticles (AgNPs) were prepared by electrospinning process. Biobased highly elastic PU was prepared from hexamethylene diisocyanate (HDI) and isosorbide/polycarbonate diol (8/2) by a simple one-shot bulk polymerization. AgNPs were formed using simple thermal reduction of silver 2-ethylhexylcarbamate at $120^{\circ} \mathrm{C}$. The structural and morphological properties of PU/Ag nanofibers were characterized by X-ray diffraction (XRD), and scanning electron microscopy (SEM). The PU nanofiber fabrics were flexible, with breaking strains from $355 \%$ to $950 \%$ under 7.28 to $23.1 \mathrm{MPa}$ tensile stress. The antibacterial effects of the treated PU/Ag fabrics against Staphylococcus aureus and MRSA were examined and found to be excellent. Cell proliferation using the immortalized human keratinocyte HaCaT cell line was performed in order to determine cell viability in the presence of PU and PU/Ag fabrics, showing cytocompatiblility and a lack of toxicity.
\end{abstract}

Keywords: Isosorbide; Elastomeric polyurethane; Dermal wound healing; Electrospun nanofibers; Silver nanoparticles; Silver carbamate; Thermal reduction 


\section{Introduction}

Nanoscale materials are increasingly being developed as antimicrobial products due to their high surface area-to-volume ratio and unique chemical and physical properties. ${ }^{1}$ Hospitals use silver treatment to dress scars and wounds, especially wounds that resist healing. Catheters are lined with silver to prevent infection and water is purified with silver. Now, silver is coming to the at-home health care market. ${ }^{2}$ Silver is incorporated into the wound pad of new bandages, which come in a variety of sizes. Such bandages can be used to treat cuts, scrapes, and burns. No antibacterial spray or ointment (such as Neosporin) should be used with these bandages because it may hamper the healing properties of the silver. ${ }^{3,4,5}$ Silver interferes with bacteria in at least three ways: by interacting with the cell membrane, by binding to DNA, and by blocking bacterial metabolism. It reduces the growth of hundreds of different types of bacteria, including some that do not normally react to pharmaceutical antibacterial agents. Because silver blocks the growth and spread of germs through multiple mechanisms, it is hard for bacteria to build up resistance to it. ${ }^{6,7}$ Silver nanoparticles have many advantages, such as unique antimicrobial properties, low cost, and versatility of application; they have been used in many commercial products, such as wound healing materials, antimicrobial coatings, fillers, and medical biotextiles. $^{7,8}$

1,4:3,6-Dianhydro- $D$-sorbitol (isosorbide) is a bio-based diol, and it is the only one possibly produced from starch at the industrial scale. Isorsobide as a sugar diol is non-toxic, and demonstrates thermal and chemical stabilities. ${ }^{9}$ It contains two cycloaliphatic rings likely to bring a good inflexible to the polyurethane (PU). ${ }^{10}$ In recent years, PUs based on isosorbide and polyol have been studied and exploited in applications. However, the application potential of the isorsobide based PU materials is far from being exploited and therefore detailed studies of the structure-properties relationship of well-defined materials are needed. ${ }^{9}$

Polymer nanofiber webs have been fabricated using an electrospinning process driven by an electrically charged jet of polymer solution. ${ }^{12}$ In recent years, there has been much research into PU nanofibers because of their mechanical properties and their usefulness in a wide variety 
of applications, such as in wound dressing materials, artificial vessels, and artificial hearts. ${ }^{13} \mathrm{~A}$ wound that is healing generally needs regular bandage changes and cleaning in order to grow new tissue and avoid the risk of infection. Hydrophilic PU foam dressing has a relatively a high moisture vapor transmission rate, absorptivity, and absorption rate, and is not directly attached to a wound. ${ }^{14}$ As a way to modify both the biological and physical properties of a highly elastic PU, it was blended with Ag nanoparticles (AgNPs) to take advantage of their antimicrobial, biocompatible, and non-toxic properties. ${ }^{15} \mathrm{PU} / \mathrm{Ag}$ nanocomposites have several advantages. Dressings made of such materials are easy to use and provide a warm, moist healing environment that protects and cleanses a wound and facilitates the body's natural healing process; they also have wide-spectrum antimicrobial efficacy against bacteria. ${ }^{16}$ Controlled release mechanisms can reduce the dose-related systemic toxicity of silver ions and increase local antibacterial activity. ${ }^{17,18}$

In this work, a bio-based, isosorbide-containing, highly elastic polyurethane and silver carbamate precursor solution was electrospun. It should be noted that PU/Ag nanofiber fabrics have been prepared without the use of any reducing agent to produce pure AgNPs after simple thermal reduction at $120^{\circ} \mathrm{C}$. ${ }^{19}$ Moreover, the thermal properties and mechanical strength of the obtained nanofiber fabrics were investigated. Also, the antimicrobial properties against Staphylococcus aureus and methicillin resistant staphylococcus aureus (MRSA) and cell cytotoxicity against the immortalized human keratinocyte HaCaT cell line were assessed. The results indicate that the prepared PU/Ag nanofiber fabrics could be are a good candidate for many biological applications, such as prolonged dermal wound healing and dressing materials. 


\section{Experimental}

\section{Materials}

The polycarbonate diol (PCD, T4672, MW=2000, Japan) was supplied by Asahi Kasei Chemicals Corporation. PCD was dried under vacuum at $60{ }^{\circ} \mathrm{C}$ before use. Hexamethylene diisocyanate (HDI, 98\%) and 1,4:3,6-dianhydro- $D$-sorbitol (isosorbide, 98\%) and 1,1,1,3,3,3hexafluoro-2-propanol (HFIP, 99\%) were purchased from Sigma-Aldrich (St. Louis, MO, USA). Isosorbide was used after drying at $40{ }^{\circ} \mathrm{C}$ under vacuum for $6 \mathrm{~h}$. Silver 2-ethylhexylcarbamate were supplied by Inktec Co. LTD (Gyunggido, Koeea). N,N-Dimethylformamide (DMF) and 2propanol were purchased from Duksan Chem. Co. Ltd. (Seoul, Korea).

\section{Instruments}

Tensile strength and elongation at break of the PUs were measured on an Instron universal testing machine (Model 3344, Instron Engineering Corp., Canton, MA, USA) at a crosshead speed of $10 \mathrm{~mm} / \mathrm{min}$ at room temperature. Polymer films were prepared by solvent casting in DMF at a $10 \%$ polymer concentration followed by air drying to give films of $0.20 \mathrm{~mm}$ thickness. The samples of PU film were cut in dumbbell shape. The results reported are the mean values for five replicates an experiment. Contact angle of the PU/Ag nanofiber fabrics were evaluated based on equipment (Phoenix 300, Surface Electro Optics, Korea). Scanning electron microscopic (SEM) photographs were obtained using a SEM (Model JSM-5410LV, JEOL, Tokyo, Japan) at a magnification of 1000x or 1500x.

\section{Material Characterization}

DSC data were recorded with a DSC (SEIKO Exstar 7020, Tokyo, Japan) instrument. Specimens $(\sim 10 \mathrm{mg})$ were sealed in a DSC Al pan before being placed in the calorimeter, cooled to $-70{ }^{\circ} \mathrm{C}$, and then heated to $300{ }^{\circ} \mathrm{C}$ at a rate of $10{ }^{\circ} \mathrm{C} / \mathrm{min}$ using a nitrogen atmosphere. TGA tests were conducted on the samples using Shimadzu TGA 50 (Shimadzu, Tokyo, Japan) equipment operating from $30{ }^{\circ} \mathrm{C}$ to $600{ }^{\circ} \mathrm{C}$ at a heating rate of $10{ }^{\circ} \mathrm{C} / \mathrm{min}$ and under a nitrogen atmosphere. The weight average $\left(M_{w}\right)$ and number average $\left(M_{n}\right)$ molecular weights of the PUs 
were measured by GPC using a Futecs NP4000 instrument (Futecs, Seoul, South Korea) equipped with a model P-4000 pump, a model AT-4000 column oven, GPC KF-804 column, and a Shodex (Shodex, Japan) R1-101 refractive index detector. Tetrahydrofuran (THF) was used as the eluent at a flow rate of $1.0 \mathrm{~mL} / \mathrm{min}$, and a sample concentration of $2.5 \mathrm{mg} / \mathrm{mL}$ was used. Polystyrene $(\mathrm{Mw}=2000,7000,12,000,65,000$, and 120,000) was used as the standard.

\section{Synthesis of high elastic polyurethanes (PU)}

In a four-necked round-bottomed flask $(250 \mathrm{~mL})$ equipped with a mechanical stirrer, thermometer, and condenser, PCD (47.56 g, $23.78 \mathrm{mmol})$ and isosorbide (13.90 g, $95.12 \mathrm{mmol})$ were placed and heated at $80{ }^{\circ} \mathrm{C}$ for $1 \mathrm{~h}$ under a dry nitrogen atmosphere. After the mixture of two diols was melted thoroughly, HDI (20 g, $118.91 \mathrm{mmol})$ was added and vigorously stirred for 5 min with a nitrogen flush. The reaction mixture was poured into a Teflon lined autoclave reactor and heated at $120^{\circ} \mathrm{C}$ to polymerize for $12 \mathrm{~h}$. After the synthesized PU was dissolved in DMF, the resulting PU solution was filtered. The filtrate was precipitated into a large amount of 2-propanol and washed with methanol. The PU product was dried at $50^{\circ} \mathrm{C}$ for $24 \mathrm{~h}$ under vacuum. PU (10 g) was dissolved in DMF (90 g) at room temperature. The PU film was cast from the PU solution on a Teflon dish to stand for $24 \mathrm{~h}$ at $60^{\circ} \mathrm{C}$. The PU films was dried at $40{ }^{\circ} \mathrm{C}$ for $12 \mathrm{~h}$ in vacuo. The average thickness of the dried PU films was $0.20 \pm 0.02 \mathrm{~mm}$. Films of average thickness were used for mechanical and degradation testing.

\section{Preparation of polyurethane/silver precursor solution}

To make precursors for electrospun PU and Ag nanofibers, PU solution was prepared by dissolving PU (1 g) in HFP (9 g) with stirring for $5 \mathrm{~h}$ at room temperature. Silver precursor solution was prepared by mixing silver 2-ethylhexylcarbamate (1 g) and 2-propanol (9 g). Finally, a PU and Ag precursor solution was prepared by mixing the above PU solution (10 g) and a silver precursor solution for $12 \mathrm{~h}$ at room temperature. Other PU/Ag precursor solutions were prepared according to the above procedures using different amounts of silver 2ethylhexylcarbamate solution. 
The PU and Ag precursor solution was loaded into a plastic syringe $(10 \mathrm{~mL})$ with a 24 gauge stainless-steel needle. The applied voltage for electrospray was $17 \mathrm{kV}$. The nanofibers were collected on a metal collector wrapped with aluminum foil and kept at a fixed distance of $20 \mathrm{~cm}$ from the needle tip of the spinneret, and a solution feed rate of $1.5 \mathrm{~mL} / \mathrm{h}$ was maintained using a syringe pump (KDS100, NanoNC, Korea). A high voltage power supply (HV30, NanoNC, Korea), capable of generating voltages up to $30 \mathrm{kV}$, was used as an electric field source. PU/Ag precursor solution was supplied through a glass syringe $(10 \mathrm{~mL})$ attached to a capillary tip. Copper wire originating from the positive electrode (anode) was inserted into the polymer solution and a negative electrode (cathode) was attached to a metallic collector. The solutions were electrospun at $17 \mathrm{kV}$ at a $15 \mathrm{~cm}$ working distance (the distance between the needle tip and the collector). The obtained PU and silver composites were termed PU/Ag. After electrospinning, the PU/Ag nanofibers were dried at room temperature for $24 \mathrm{~h}$ to remove residual solvent. Then, $\mathrm{PU} / \mathrm{Ag}$ nanofiber fabrics were transformed in a convection oven maintained at $120^{\circ} \mathrm{C}$ for $15 \mathrm{~min}$ to reduce the silver carbamate to silver.

\section{Silver ion release test}

To measure the dynamic release of silver ions, clean PU/Ag nanofiber fabrics $(1 \mathrm{~cm} \mathrm{x} 1 \mathrm{~cm})$ were put into deionized water; then, the silver ion concentration of the solution was measured between 1 and 21 days using an inductive coupled plasma mass spectrometer. In order to attain uniform concentration, the solutions were homogenized by occasional shaking as well as by shaking the flasks just prior to the withdrawal of the analytes for inductive coupled plasma mass spectrometry experiments.

\section{Cell Culture and determination of cell viability}

The immortalized human keratinocyte HaCaT cell line was cultured at $37^{\circ} \mathrm{C}$ in Dulbecco's modified Eagle's medium (DMEM, Thermo Fisher Scientific, MA, USA) supplemented with 10\% fetal bovine serum (FBS, Thermo Fisher Scientific, MA, USA) and 100 units $/ \mathrm{ml}$ penicillin/streptomycin. To determine cell viability in the presence of PU and PU/Ag fabrics, a 
Briefly, PU samples were placed in 12-well culture plates and then washed with DPBS (pH 7.4). HaCaT cells were plated at a density of $4 \times 10^{4}$ cells per well and cultured for 7 days in culture media and the MTT assay was performed on days 1, 3, 5, and 7. For the MTT assay, cells were incubated with $300 \mu \mathrm{L}$ of MTT $(0.5 \mathrm{mg} / \mathrm{mL})$ for $4 \mathrm{~h}$ at $37^{\circ} \mathrm{C}$. After incubation, MTT was removed and dimethylsulphoxide (DMSO, $200 \mu \mathrm{L}$ ) was added to each well, the concentration of which was measured at $540 \mathrm{~nm}$ using a microplate reader (SpectraMax M2e, Molecular Devices, CA, USA). The values are expressed as fold changes. The analysis was performed in three independent experiments using three separate wells each time.

\section{Antibacterial assessment of PU/Ag nanofiber fabrics}

The antibacterial activity of PU and PU/Ag nanofiber fabrics was evaluated by means of an agar diffusion method ${ }^{20}$ and turbidity assay $^{21}$ using Staphylococcus aureus (S. aureus) and Methicillin-Resistant Staphylococcus aureus (MRSA) multidrug resistant clinical isolates. For agar diffusion, pristine PU and PU/Ag membranes were cut into $15 \mathrm{~mm}$ disks and placed on a, LB agar plate containing $1 \times 10^{5} \mathrm{CFU} / \mathrm{mL}$ of S. aureus or MRSA. The plates were incubated overnight at $37^{\circ} \mathrm{C}$, and then the average diameter of the inhibition zones underneath and around each sample were measured. For the turbidity assay, the antibacterial activity of PU nanofiber fabrics was evaluated quantitatively by measuring the optical density (OD) at $600 \mathrm{~nm}$. Briefly, bacteria were pre-cultured overnight at $37^{\circ} \mathrm{C}$ in an orbital shaker at $180 \mathrm{rpm}$ to prepare a culture in logarithmic growth phase for the antibacterial test. Then, polyurethane disk samples were dipped into a $15 \mathrm{~mL}$ Falcon tube containing $5 \mathrm{~mL}$ of LB broth (peptone $10 \mathrm{~g} / \mathrm{L}$, yeast extract 5 $\mathrm{g} / \mathrm{L}, \mathrm{NaCl} 5 \mathrm{~g} / \mathrm{L}, \mathrm{pH} 7.4$ ) and $1.5 \times 10^{4} \mathrm{CFU}$ of S. aureus or MRSA. Growth rate was monitored by OD measurements at $4,8,12,16$, and $24 \mathrm{~h}$. The OD of the culture solution $(200 \mu \mathrm{L})$ was measured at $600 \mathrm{~nm}$ using a microplate reader (SpectraMax M2e, Molecular Devices, CA, USA). 


\section{Results and discussion}

\section{Preparation of highly elastic polyurethane}

Our one-pot polymerization process is very simple and reduces the risk of toxicity from a surfactant or catalyst. Polymerization of hexamethylene diisocyanate (HDI) and diols with varying ratios of polycarbonate diol (PCD) to isosorbide was carried out by one-pot polymerization via an addition-condensation reaction without a catalyst, as shown in Fig. 1. The optimal ratio of PCD to isosorbide was determined with consideration of the elastic behaviors of $\mathrm{PU}^{22-24}$ The ratio of $\mathrm{PCD}$ to isosorbide was $\mathrm{PCD} /$ isosorbide $=2 / 8$. Isosorbide showed poor miscibility in PCD and HDI, indicating that the isosorbide was more hydrophilic than the PCD and HDI. Thus, the polymerization of HDI with $\mathrm{PCD} /$ isosorbide $=2 / 8$ was carried out after premixing a solution of the three monomers at $80^{\circ} \mathrm{C}$. Finally, polymerization was performed at $120^{\circ} \mathrm{C}$ for $12 \mathrm{~h}$. The number and weight average molecular weights $\left(\mathrm{M}_{\mathrm{n}}\right.$ and $\left.\mathrm{M}_{\mathrm{w}}\right)$ obtained from gel permeation chromatography (GPC) were 106,800 and 56,400, respectively.

\section{$<$ Fig. 1 $>$}

\section{Preparation of electrospun PU/Ag nonofiber fabrics}

After the blend of PU and silver carbamate solution was electrospun, the nanofiber fabrics were heated at $120^{\circ} \mathrm{C}$ as illustrated in Scheme 1. A silver alkylcarbamate was heated at 100$130^{\circ} \mathrm{C}$ for a few minutes, resulting in its quantitative conversion to silver nanoparticles, carbon dioxide, and alkyl amine as follows: $\mathrm{Ag}_{2}(\mathrm{OCONHR})+\mathrm{H}_{2} \mathrm{O} \rightarrow 2 \mathrm{Ag}+2 \mathrm{RNH}_{2}+2 \mathrm{CO}_{2}+1 / 2$ $\mathrm{O}_{2}$. The fabrics would quickly turn dark and then gradually change to a light yellow to brown color according to silver carbamate content. The dark color indicated that the silver carbamate decomposed and then gradually agglomerated into extremely fine silver nanoparticles that were distributed in the solid PU matrix. UV-vis spectroscopy is useful for characterizing metal nanoparticles. We verified the formation of silver nanoparticles by the UV-vis spectra. Fig. 2 shows the UV-vis spectrum of PU/Ag nanofiber fabrics obtained from PU and silver carbamate solution. The silver surface plasmon indicates the existence of silver nanoparticles in the 
solution. The UV-vis spectra for the PU/Ag films heated at $120^{\circ} \mathrm{C}$ shows only one absorption peak around $420 \mathrm{~nm}^{25,26}$

\section{$<$ Scheme 1 $><$ Fig. 2 $>$}

\section{TEM images}

Fig. 3 shows transmission electron microscope (TEM) images of PU/Ag $(0.01,0.1,1$, and 5 wt $\%$ ) nanofiber fabrics after thermal reduction. AgNPs at concentrations of $0.01-5 \%$ were detected in the direction of the fibers. The AgNPs were dispersed in a solid PU matrix. In all the combinations ranging from 0.01 to $5 \mathrm{wt} \%$ silver concentration, AgNPs with a uniform deposition density formed in the PU matrix and ranged in size from 20 to $30 \mathrm{~nm}$ for $\mathrm{PU} / \operatorname{Ag}(0.01 \%), \mathrm{PU} / \operatorname{Ag}(0.1 \%)$ and $\mathrm{PU} / \operatorname{Ag}(1.0 \%)$. PU/Ag(5\%) showed spherical in shape and had a size range between 20 and $40 \mathrm{~nm}$ with an average of $30 \mathrm{~nm}$. Moreover, the incidence of AgNPs increased as the concentration of silver carbamate increased in the original solutions used for electrospinning. It was shown that silver nanoparticles were distributed uniformly in PU/Ag nanofibers made using silver carbamate complex, without aggregation. ${ }^{27,28}$

\section{$<$ Fig. 3 $>$}

\section{SEM images}

Fig. 4 shows SEM images of the nanofiber fabrics made with different concentrations of AgNPs in the PU matrix, which were prepared by thermal reduction at $120^{\circ} \mathrm{C}$ for 30 min. Importantly, fibers could form from a $10 \mathrm{wt} \% \mathrm{PU}$ solution. Under this condition, smooth and uniform nanofibers were produced with diameters ranging between 500 and $1 \mu \mathrm{m}$. Beads were not observed in the nanofiber fabrics. Generally, the formation of beads has been attributed to jet instability, which presumably is reduced upon increasing solution viscosity with high molecular weight polymer. ${ }^{29}$ Morphology of the pure PU nanofiber are different from those of other samples because the PU/Ag nanofiber fabrics were heated at $120^{\circ} \mathrm{C}$ for thermal reduction. PU/Ag nanofiber fabrics containing $0.01,0.1$, and $1 \mathrm{wt} \%$ AgNPs also have smooth surfaces. ${ }^{30}$ The PU/Ag(5\%) was linked through fusion-bonding. 


\section{$X R D$ and EDS study}

The XRD patterns of PU/Ag nanofiber fabrics containing 0.01, 0.1, and 5 wt.\% Ag nanoparticles show diffraction peaks at $2 \theta$ of ca. $19.3^{\circ}, 38.2^{\circ}$, and $44.6^{\circ}$, respectively (Fig. 5A). A significant crystalline peak at about $19.3^{\circ}$ originated from the polymers, and is due to the occurrence of strong inter- and intramolecular hydrogen bonding. All the other peaks corresponded to $\mathrm{Ag}$ phases. The peaks for the $\mathrm{Ag}$ particles $\left(2 \theta=38.2^{\circ}\right.$ and $\left.44.6^{\circ}\right)$ were increased with increasing contents of Ag nanoparticles, and the crystallinity of PU $\left(2 \theta=19.3^{\circ}\right)$ was lower in comparison with that shown in Fig. 5A. These peaks correspond to the (111), (200), (220), and (311) planes of the silver nanocrystals with cubic symmetry. XRD results indicate that the Ag nanoparticles were well-dispersed in the PU nanofiber fabrics. To ensure that the AgNPs are in fact present on nanofibers, EDS analysis was utilized on one of the pristine and modified nanofibers; the results are presented in Fig. 5B. The EDS spectrum of the PU/Ag composite nanofibers contains $\mathrm{C}, \mathrm{Ag}$, and $\mathrm{O}$, and no other element is detected, indicating that the final product is free of impurities and is composed only of $\mathrm{C}, \mathrm{Ag}$, and $\mathrm{O}$. The silver peaks on the nanofiber surfaces evident by EDX analysis confirms that AgNPs can be generated from the thermal reduction of silver carbamate precursor via an electrospinning process. ${ }^{31,32,33}$

$<$ Fig. 5 $>$

\section{Thermal properties.}

It is important to understand the thermal behavior of PU developed for biomedical applications, as this determines the physical properties of the materials and their processability. Thermogravometric analysis (TGA) was used to characterize the thermal behaviors of the $\mathrm{PU} / \mathrm{Ag}$ developed in this experiment. In the DSC curves in inset figure, a weak broad endothermic peak at $70.5^{\circ} \mathrm{C}$ for PU was caused by the melting transition of the crystal domain in the thermoplastic elastomeric feature. The glass transition temperature $\left(\mathrm{T}_{\mathrm{g}}\right)$ of $\mathrm{PU}$ was $-33.9^{\circ} \mathrm{C}$, which is higher than that of poly(tetramethylene glycol)-based PUs. ${ }^{22}$ These PUs could exhibit thermoplastic elastomeric properties at body temperature. If the $\mathrm{T}_{\mathrm{g}}$ value were to be greater than body temperature, the material would be in a rigid state. 
The thermal stability of the samples was analyzed by thermogravimetric analysis under an $\mathrm{N}_{2}$ atmosphere using a temperature gradient from room temperature to $600^{\circ} \mathrm{C}$ at a heating rate of $10^{\circ} \mathrm{C} \min ^{-1}$. Fig. 6 show the pristine PU and various PU/Ag composite nanofibers with different concentrations of AgNPs. The TGA curves for the PUs nearly overlap and begin to lose its $10 \%$ weight at $327{ }^{\circ} \mathrm{C}, 323^{\circ} \mathrm{C}, 325{ }^{\circ} \mathrm{C}$ and $328{ }^{\circ} \mathrm{C}$ for $\mathrm{PU} / \operatorname{Ag}(0.01 \mathrm{wt} \%), \mathrm{PU} / \mathrm{Ag}(0.1 \mathrm{wt} \%)$, $\mathrm{PU} / \operatorname{Ag}(1.0 \mathrm{wt} \%)$ and $\mathrm{PU} / \operatorname{Ag}(5.0 \mathrm{wt} \%)$, respectively. The onset of degradation temperature of $\mathrm{PU} / \operatorname{Ag}(0.01 \mathrm{wt} \%), \mathrm{PU} / \operatorname{Ag}(0.1 \mathrm{wt} \%), \mathrm{PU} / \mathrm{Ag}(1.0 \mathrm{wt} \%)$ and $\mathrm{PU} / \operatorname{Ag}(5.0 \mathrm{wt} \%)$ is $297{ }^{\circ} \mathrm{C}, 302{ }^{\circ} \mathrm{C}$, $301{ }^{\circ} \mathrm{C}$ and $306{ }^{\circ} \mathrm{C}$, respectively. $\mathrm{PU} / \mathrm{Ag}(5 \%)$ nanofiber shows increased the thermal stability slightly as judged from its degradation temperature.

$<$ Fig. 6 $>$

\section{Measurement of contact angle}

The surfaces of the PU/Ag nanofiber fabrics were evaluated by water contact angle. As shown in Fig. 7, It is generally agreed that hydrophilic surfaces possess contact angles with water in the range $1-30^{\circ}$, whereas the contact angles of hydrophobic surfaces are $>90^{\circ}$. The PU nanofibers showed a water contact angle $<72.21^{\circ}$, whereas that of PU/Ag $(0.01 \mathrm{wt} \%)$ was $<58.82^{\circ}$, that of PU/Ag $(0.1 \mathrm{wt} \%)$ was $<53.43^{\circ}$, that of PU/Ag $(1 \mathrm{wt} \%)$ was $<51.29^{\circ}$, and that of PU/Ag $(5 \mathrm{wt} \%)$ was $<49.82^{\circ}$. As shown in Fig. 8 , an increase in the concentration of AgNPs in the PUs causes the contact angle to decrease slightly, from $49.82^{\circ}$ to $58.82^{\circ}$, which improves the hydrophilic nature of the elastic PU polymer surfaces. ${ }^{34}$

\section{$<$ Fig. 7 $>$}

\section{Mechanical properties}

The mechanical properties of the films depended on molecular weight, hard segments, and soft segments. In addition, there was a relationship between hard segments and stiffness. Stressstrain analysis (Fig. 8) was carried out using standard procedures (ASTM D 882) at an extension rate of $10 \mathrm{~mm} / \mathrm{min}$. All the nanofiber fabrics tested showed nonlinear elastic behavior in the low-stress region and plastic deformation under higher levels of stress. The stress-strain curve of the PU/Ag nanofiber fabrics changed slightly after the introduction of AgNPs. Loading AgNPs 
made nanocomposite nanofiber fabrics a bit stronger and more brittle. The effect of AgNPs in this study, however, was not considerable owing to the low content of AgNPs. The PU/Ag nanofiber fabrics were flexible, with breaking strains from $365 \%$ to $953 \%$ under tensile stresses of 8.15 to $23.6 \mathrm{MPa}$. The UTS of the films was comparable to that of the aorta $(50 \%-100 \%)$, whereas the breaking strains were generally greater than that of the aorta. The main degradable polymers used in biomedicine are polycaprolactone, polyglycolic acid, poly( $L$-lactic acid), and their derivatives. These polymers are all very stiff and are not suitable for engineering of soft tissues, even in a fibrous or woven state. ${ }^{35}$

\section{$<$ Fig. 8 $>$}

\section{Silver ion release test}

The oxidation of the metallic silver to the antimicrobial species $\mathrm{Ag}^{+}$is possible through an interaction of the AgNPs with water molecules. Silver ion, which is a versatile antimicrobial species, was released in a steady and prolonged manner from PU/Ag nanofiber fabrics. $\mathrm{Ag}^{+}$ release was observed to increase with time, as shown in Fig. 9. The initial release of silver ions (on the first day) most likely results from PU/Ag nanofiber fabrics being soaked in water, which causes an interaction of the diffused water molecules and the dispersed AgNPs within the PU matrix. $\mathrm{Ag}^{+}$release was influenced by AgNPs concentration and their nature of dispersion and the changes in physical state of the nanofiber fabrics as a result of water diffusion and composite morphology.

The Ag durability test was done by soaking the Ag-loaded PU specimens in distilled water several times, and analyzing the Ag concentration in the water using an inductive coupled plasma mass spectrometer. The findings may be explained on the basis of the fact that $\mathrm{Ag}^{+}$ions, which are oxidized and subsequently released from the internal part of the PU/Ag nanofiber fabrics, are released slowly into the surrounding fluid. The PU/Ag surfaces still show a compact and uniform covering of AgNPs. However, PU fabrics with lower silver content $(0.01 \mathrm{wt} \%)$ lead to lower $\mathrm{Ag}^{+}$release. The composites were found to release $\mathrm{Ag}^{+}$at a level capable of rendering antimicrobial efficacy. 
$<$ Fig. 9>

\section{MTT cell viability test}

Many studies have assessed biocompatibility using the 3-(4,5-dimethylthiazol-2-yl)-2,5diphenyltetrazolium bromide (MTT) assay. If cellular proliferation on $\mathrm{PU} / \mathrm{Ag}$ composite nanofibers fabrics is maintained for 1-2 weeks, then the PU/Ag can be considered cytocompatible and biocompatible. Immortalized human keratinocyte HaCaT cells were used for this assay, as they are highly sensitive to culture conditions. Cell attachment was examined with the MTT assay. The ODs at $540 \mathrm{~nm}$ for PU/Ag $(0.01 \mathrm{wt} \%)$ were $0.7,1.03,1.21$, and 1.37 after 1 , 3, 5, and 7 days in culture, respectively, and those of PU/Ag $(0.1 \mathrm{wt} \%)$ were $0.62,0.76,0.91$, and 1.09 after $1,3,5$, and 7 days in culture, respectively, indicating that the number of cells on the films increased significantly over the course of a week. The MTT absorbance values for $\mathrm{HaCaT}$ cell adhesion to and proliferation on the PU/Ag nanofibers compared to controls are shown in Fig. 10. Although the cells showed a slightly lower rate of proliferation than did controls, the PU/Ag films were considered to be cytocompatible and nontoxic. Furthermore, the synthesized PU/Ag had good mechanical strength, thermal stability, cytocompatibility, and antimicrobial properties. Attachment of cells to a material is one of the prerequisites for biocompatibility and, therefore, possible utilization in biomedical applications. ${ }^{36}$

$<$ Fig. 10 $>$

\section{Antimicrobial activity}

The antimicrobial activity of PU/Ag nanofiber fabrics was determined by the inhibition zones formed on agar medium and a direct plating method after the incubation of S. aureus and MRSA with fabrics immobilized with AgNPs. PU/Ag fabrics placed on the agar medium killed the bacteria around the fabrics as shown in Fig. 11. The average diameters of the zone of inhibition of S. aureus and MRSA were $20.41 \mathrm{~mm}$ and $18.24 \mathrm{~mm}$, respectively, with PU immobilized with a $0.01 \mathrm{wt} \%$ and $0.1 \mathrm{wt} \%$ silver carbamate solution. When the fabrics with a $0.01 \mathrm{wt} \%$ and $0.1 \mathrm{wt} \%$ silver content were applied to the agar medium, the average zones of inhibition increased. Untreated PU, as a negative control, did not show any antimicrobial 
activity. The antimicrobial effects of PU/Ag were also assessed in LB broth as shown in Fig. 12. $1 \times 10^{4} \mathrm{CFU}$ of each bacterium were inoculated into $1 \mathrm{~mL}$ of LB medium containing PU/Ag with $0.01 \mathrm{wt} \%$ and $0.1 \mathrm{wt} \%$ silver content. PU (positive control) had no antibacterial effect on any MRSA or S.aureus strains. PU/Ag $0.01 \mathrm{wt} \%$ maintained antibacterial activity against both MRSA and S.aureus for $8 \mathrm{~h}$, and growth inhibition was maintained for 24 by PU/Ag $0.1 \mathrm{wt} \%$. These results indicate that silver ions are effectively released from PU/Ag fabrics on contact with moisture, and PU/Ag fabrics have powerful antimicrobial activities against both gram positive S. aureus and MRSA. ${ }^{35,37,38}$

\section{$<$ Fig. 11 $><$ Fig. 12 $>$}

\section{Conclusions}

Nano-biotechnologically engineered PU/Ag nanofiber fabrics can be easily electrospun from PU and silver carbamate precursor solutions, followed by simple thermal treatment at $120{ }^{\circ} \mathrm{C}$. Interestingly, the presence of AgNPs in the PU nanofiber matrix distinctly improves physicochemical properties, including thermal, mechanical, and biological properties. Another advantage of the current nanocomposite is its antibacterial properties. Also, a cytotoxicity test was conducted to ensure that the PU/Ag nanofiber provided a suitable environment for cell attachment and spreading of $\mathrm{HaCaT}$ cells cultured on the PU/Ag nanofiber fabrics for 1-7 days. The process outlined herein provides a convenient, non-toxic, non-denaturing approach for the generation of highly elastic polyurethane/AgNPs nanofiber fabrics and non-woven fabrics that have potential applications in wound healing, tissue engineering scaffolds, filtration and sensors.

\section{Funding}

The author(s) disclosed receipt of the following financial support for the research, authorship, and/or publication of this article: This study was supported by Priority Research Centers Program (no. 2009-0093829) through the National Research Foundation of Korea. 


\section{References}

1. Bhushan B, Luo D, Schricker SR, Sihmund W, Zauscher S (Eds). Handbook of Nanomaterials Properties. Springer, 2014: 1053-75.

2. Beattie M, Taylor J. Silver alloy vs. uncoated urinary catheters: a systematic review of the literature. J Clinical Nursing 2011; 20: 2098-108.

3. Wang X, Cheng F, Gao J, Wang L, Antibacterial wound dressing from chitosan/polyethylene oxide nanofibers mats embedded with silver nanoparticles. J Biomater Appl 2015; 29: 1086-1095.

4. Bosetti M, Masse A, Tobin E, Cannas M, Silver coated materials for external fixation devices: in vitro biocompatibility and genotoxicity. Biomater 2002; 23: 887-92.

5. Bulman SEL, Goswami P, Tronci G, Russell SJ, Carr C. Investigation into the potential use of poly(vinyl alcohol)/methylglyoxal fibres as antibacterial wound dressing components, $\mathrm{J}$ Biomater Appl, 2015; 29: 1193-1200.

6. Morones-Ramirez JR, Winkler JA, Spina CS, Collins JJ. Silver enhances antibiotic activity against gram-negative bacteria. Sci Trans. Med 2013; 5: 1-11.

7. Haase A, Mantion A, Graf P, Plendl J, Thuenemann AF, Meier W, Taubert A, Luch A. A novel type of silver nanoparticles and their advantages in toxicity testing in cell culture systems. Archiv Toxicology 2012; 86: 1089-98.

8. Manjumeena R, Elakkiya T, Duraibabu D, Feroze Ahamed A, Kalaichelvan PT, Venkatesan R, Green' biocompatible organic-inorganic hybrid electrospun nanofibers for potential biomedical applications. J Biomater Appl， 2015; 29: 1039-1055.

9. Fenouillot-Rimlinger F, Rousseau A, et al. Isosorbide, a green diol for polymers. In: Proceedings of 2010 43rd IUPAC Word Polymer Congress, Glasgow, UK, 11-16 July 2010. 27.

10. Besse V, Auvergne R, et al. Synthesis of isosorbide based polyurethanes: An isocyanate free method. React Funct Polym 2013; 73: 588-94.

11. Špirkova M, Pavlicěvic J, Strachota A, et al. Novel polycarbonate-based polyurethane elastomers: Composition-property relationship. Eur Polym J 2011; 47: 959-72.

12. Fadkari SB. Scaling analysis for electrospinning. Springer Plus 2014; 3: 705. 
13. Karakas H, Sarac AS, Polat T, Budak EG, Bayram S, Dag N, Jahangiri S. Polyurethane nanofibers obtained by electrospinning process. In Scholarly Scientific Res Innovation 2013; 7: $177-80$

14. Honeycutt TW. Polyurethane form Dressing. USP 4960594. (1990).

15. Tran QH, Nguyen VQ, Le AT. Silver nanoparticles: Synthesis, properties, toxicology, applications and perspectives. Adv Nat Sci 2013; 4: 1-20.

16. Deka H, Karak N, Kalita RD, Buragohain AK. Bio-based thermostable, biodegradable and biocompatible hyperbranched polyurethane/Ag nanocomposites with antimicrobial activity. Polym Degrad Stab 2010; 95: 1509-17.

17. Prabhu S, Poulose EK. Silver nanoparticles: mechanism of antimicrobial action, synthesis, medical applications, and toxicity effects. Int Nano Lett 2012; 2: 1-10.

18. Calamak S, Aksoy EA, Ertas N, Erdogdu C, Sagıroglu M, Ulubayram K, Ag/silk fibroin nanofibers: Effect of fibroin morphology on $\mathrm{Ag}^{+}$release and antibacterial activit. Eur Polym $\mathrm{J}$ 2015; 67: 99-112.

19. Kim KA, Cha JR, Gong MS. Facile preparation of silver nanoparticles and application to silver coating using latent reductant from a silver carbamate complex. Bull Korean Chem Soc 2013; 34: 505-9.

20. Ryan MP, Rea MC, Hill C, Ross RP. An application in cheddar cheese manufacture for a strain of Lactococcus lactis producing a novel broad-spectrum Bacteriocin, Lacticin 3147. Appl Environ Microbiol 1996; 62: 612-9.

21. Gurunathan S, Han JW, Dayem AA, Eppakayala V, Kim JH. Oxidative stress- mediated antibacterial activity of graphene oxide and reduced graphene oxide in pseudomonas aeruginosa. Int J Nanomed 2012; 7: 5901-14.

22. Oh SY, Kang MS, Knowles JC, Gong MS., Synthesis of bio-based thermoplastic polyurethane elastomers containing isosorbide and polycarbonate diol and their biocompatible properties. J Biomater Appl 2015; 30: 327-37.

23. Kim HJ, Kang MS, Knowles JC, Gong MS. Synthesis of highly elastic biocompatible polyurethanes based on bio-based isosorbide and poly(tetramethylene glycol) and their properties. J Biomater Appl 2014; 29: 454-64.

24. Park HS, Gong MS, Park JH, Moon SI, Wall IB, Kim HW, Lee JH, Konwles JC. Silk fibroin-polyurethane blends: Physical properties and effect of silk fibroin content on 
viscoelasticity, biocompatibility and myoblast differentiation. Acta Biomaterialia 2013; 9: $8962-71$.

25. Cocca M, Orazio LD. Novel silver/polyurethane nanocomposite by in situ reduction: Effects of the silver nanoparticles on phase and viscoelastic behavior. J Polym Sci Part B: Polym Phys 2008; 46: 344-50.

26. Qu R, Gao J, Tang B, Ma Q, Qu B, Sun C. Preparation and property of polyurethane/nanosilver complex fibers. Appl Surf Sci 2014; 294: 81-8.

27. Khalil KA, Fouad H, Elsarnagawy T, Almajhdi FN. Preparation and characterization of electrospun PLGA/silver composite nanofibers for biomedical applications. Int $\mathrm{J}$ Electrochem 2013; 8: 3483-93.

28. Jeon HJ, Kim JS, Kim TG, Kim JH, Yu WR, Youk JH, Preparation of poly(caprolactone)based polyurethane nanofibers containing silver nanoparticles. Appl Surf Sci 2008; 254: 588690.

29. Huang L, Naqapudi K, Apkarian RP, Chaikof EL. Engineered collagen-PEO nano fibers and fabrics. J Biomater Sci Polym Edn 2001; 12: 979-93.

30. Park JH, Kim IK, Choi JY, Karim MR, Cheong IW, Oh W, Yeum JH. Electrospinning fabrication of poly(vinyl alcohol)/waterborne polyurethane/silver composite nanofibre mats in aqueous solution for anti-bacterial exploits. Polym Polym Composites 2011; 19: 753-61.

31. Kim KY, Gong MS, Park CK, Preparation of highly stabilized silver nanopowders by the thermal reduction and their properties. Bull Korean Chem Soc 2012; 33: 3987-92.

32. Kwak WG, Oh MH, Gong MS, Preparation of silver-coated cotton fabrics using silver carbamate via thermal reduction and their properties, Carbohyd Polym 2015; 115:317-24.

33. Ahn HY, Cha JR, Gong MS, Preparation of sintered silver nanosheets by coating technique using silver carbamate complex, Mater Chem Phys 2015; 153: 390-95.

34. Amarjargal A, Tijing LD, Shon HK, Park CH, Kim CS. Facile in situ growth of highly monodispersed Ag nanoparticles on electrospun PU nanofiber membranes: Flexible and high efficiency substrates for surface enhanced Raman scattering. Appl Surf Sci 2014; 308: 396-401.

35. Sheikh FA, Barakat NAM, Kanjwal MA, Jeon SH, Kang HS, Kim HY. Self synthesize of silver nanoparticles in/on polyurethane nanofibers: Nano-biotechnological approach. J Appl Polym Sci 2010; 115: 3189-98. 
36. Mosmann T. Rapid colorimetric assay for cellular growth and survival: Application to proliferation and cytotoxicity assays. J Immunol Methods 1983; 65: 55-63.

37. Kim SH, Lee HS, Ryu DS, Choi SJ, Lee DS. Antibacterial activity of silver- nanoparticles against Staphylococcus aureus and Escherichia coli. Korean J Microbiol 2011; 39: 77-85.

38. Paul D, Paul S, Roohpour N, Wilks M, Vadgama P. Antimicrobial, mechanical and thermal studies of silver particle-loaded polyurethane. J Funct Biomater 2013; 4: 358-75. 


\section{Figure Captions}

Fig. 1. Schematic structure of thermoplastic polyurethane synthesized from polycarbonate diol, isosorbide and HDI.

Fig. 2. UV-vis spectra of PU/Ag nanofiber fabrics with different Ag content.

Fig. 3. TEM images of PU/Ag electrospun nanofibres containing different content of silver; (a) $0.01 \mathrm{wt} \%$, (b) $0.1 \mathrm{wt} \%$, (c) $1 \mathrm{wt} \%$ and (d) $5 \mathrm{wt} \%$.

Fig. 4. SEM image of (a) pristine PU and (b) PU/Ag (0.01 wt\%), (c) PU/Ag (0.1 wt\%), (d) PU/Ag (1 wt \%) and (e) PU/Ag (5 wt\%).

Fig. 5. (A) XRD patterns of a) PU/Ag nanofiber fabric with $0.1 \mathrm{wt} \%$ silver and (b) pristine PU, and (B) energy-dispersive spectroscopy (EDS) spectrum of PU/Ag Nanofiber fabrics.

Fig. 6. TGA analysis of pristine PU and PU/Ag nanofiber fabrics: inset figure is DSC curve of pure PU.

Fig. 7. Contact angle images of (a) pristine PU and (b) PU/Ag (0.01 wt\%), (c) PU/Ag (0.1 wt\%), (d) PU/Ag (1 wt \%) and (e) PU/Ag (5 wt\%).

Fig. 8. Tensile strain vs tensile stress curves of thermoplastic PU/Ag nanofiber fabrics.

Fig. 9. Silver ion $\left(\mathrm{Ag}^{+}\right)$release after immersing sample in water.

Fig.10. The MTT cell viability of control cells were set $100 \%$, and viability relative to the control was expressed.

Fig. 11. The plate morphology of (A) S. aureus and (B) MRSA cells exposed to (a) pristine PU, (b) PU/Ag (0.01 wt\%) and (c) PU/Ag (0.1 wt\%) nanofiber fabrics.

Fig. 12. Growth curve of (A) S. aureus and (B) MRSA cells exposed to no nothing medium, pristine PU, PU/Ag (0.01 wt\%) and PU/Ag (0.1 wt\%) nanofiber fabrics.

Scheme 1. Schematic diagram of preparation of PU/AgNPs nanofiber fabrics by thermolysis using silver carbamate complex. 
Table 1. Water contact angle of PU/Ag nanofiber fabrics.

\begin{tabular}{ccc}
\hline Sample & Silver content $(\%)$ & Water contact angle $\left(^{\circ}\right)$ \\
\hline PU $^{\mathrm{a}}$ & 0 & $72.21 \pm 1.32$ \\
\hline PU/Ag & & \\
\hline PU/Ag $(\mathbf{0 . 0 1} \mathbf{~ w t} \%)$ & 0.01 & $58.82 \pm 1.02$ \\
\hline PU/Ag(1.0 wt\%) & 0.1 & $53.43 \pm 0.92$ \\
\hline PU/Ag(5.0 wt\%) & 1.0 & $51.29 \pm 1.01$ \\
\hline
\end{tabular}

${ }^{\mathrm{a}}$ Polyurethane.

${ }^{\mathrm{b}} \mathrm{PU} / \mathrm{Ag}$ nanofiber fabrics. 


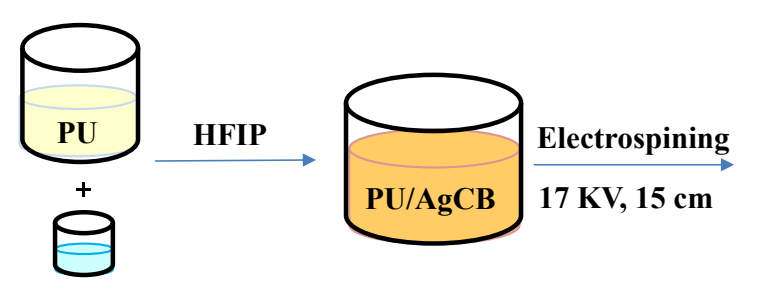

Ag carbamate

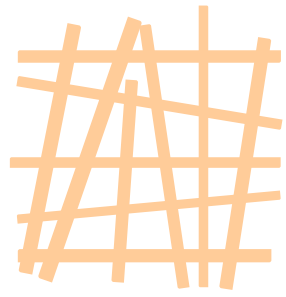

Thermal Reduction

$120^{\circ} \mathrm{C}$ $15 \min$

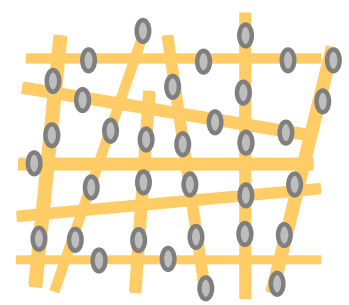

PU+ Ag carbamate Nanofiber
Siver Nanoparticle
PU+ Ag carbamate solution

Scheme 1. Schematic diagram of preparation of PU/AgNPs nanofiber fabrics by thermolysis using silver carbamate complex.

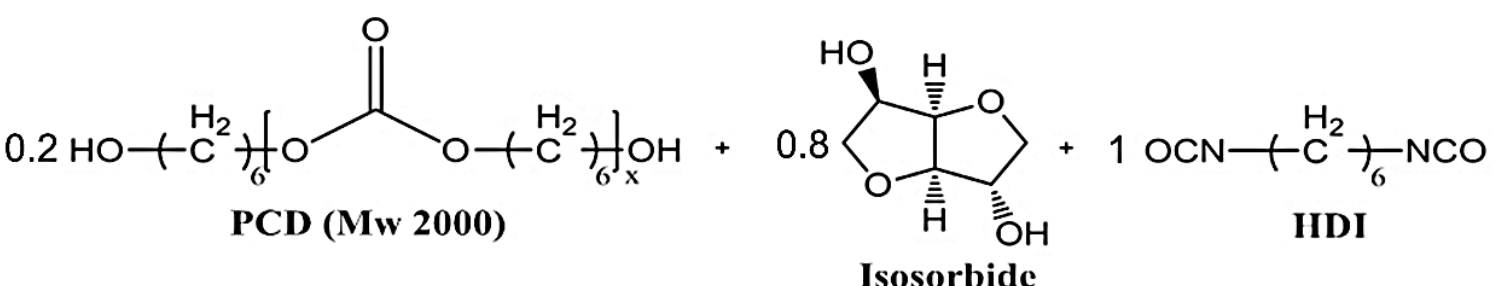

Isosorbide

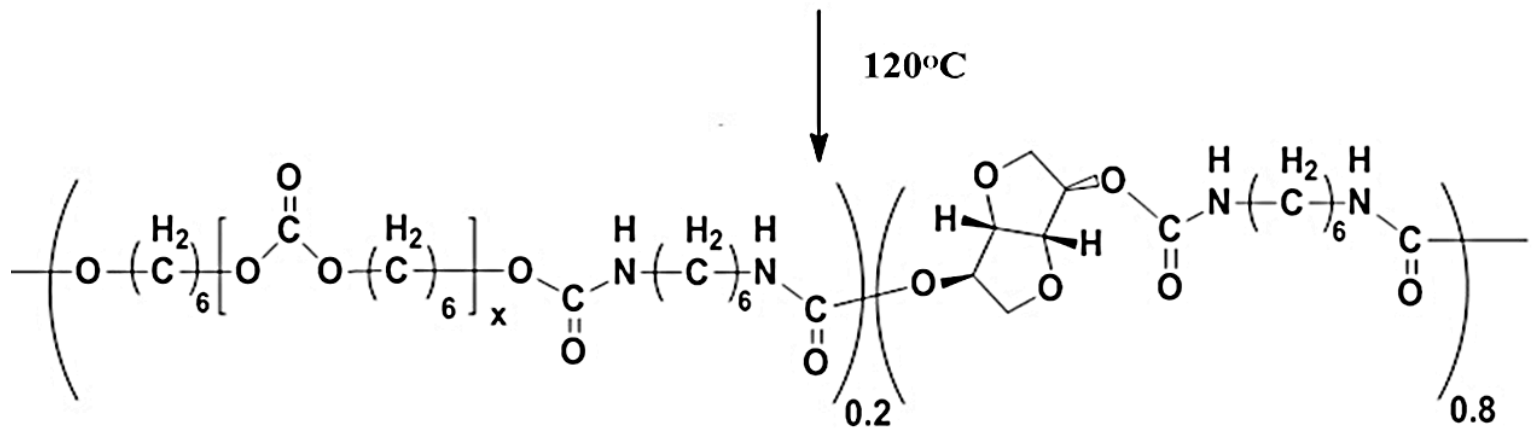

Fig. 1. Schematic structure of thermoplastic polyurethane synthesized from polycarbonate diol, isosorbide and HDI. 


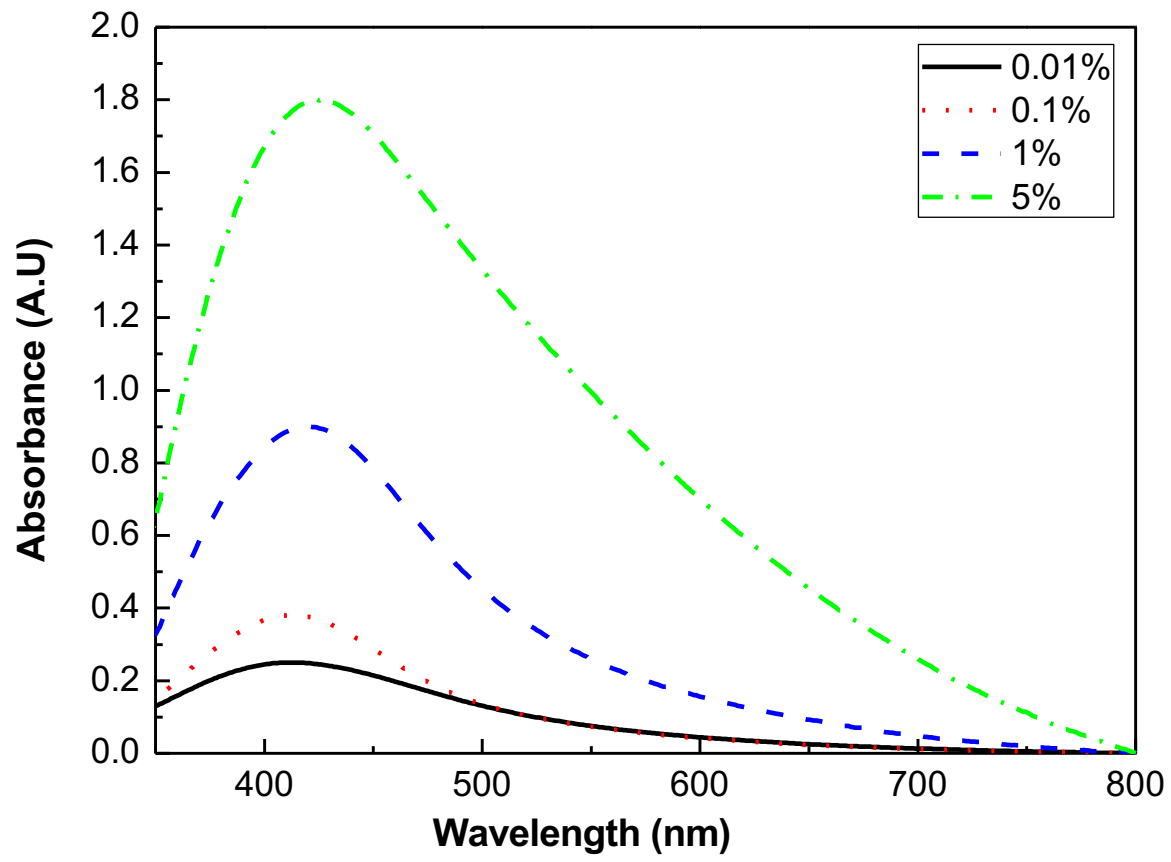

Fig. 2. UV-vis spectra of PU/Ag nanofiber fabrics with different Ag content. 


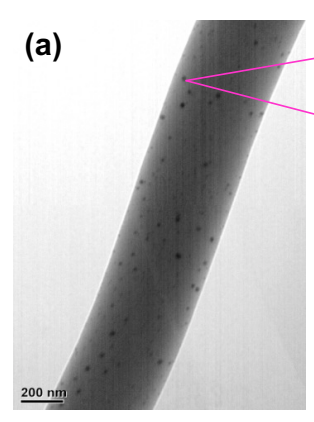

(c)

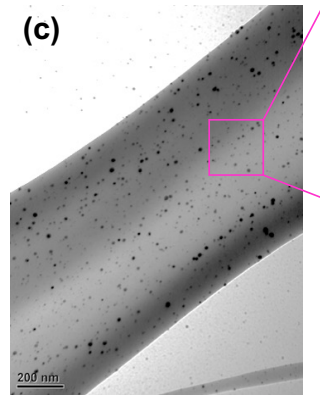

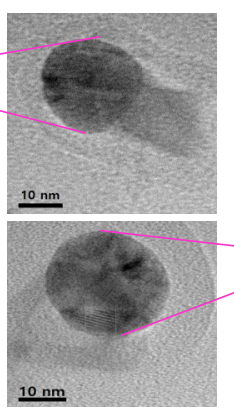

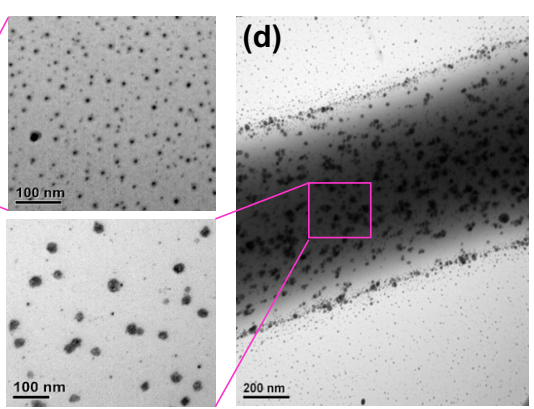

(b)

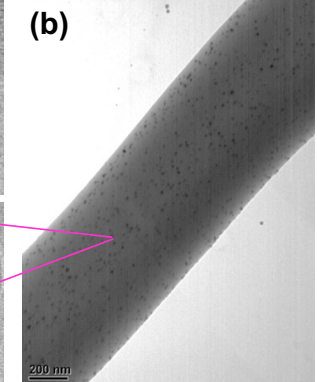

(d)

Fig. 3. TEM images of PU/Ag electrospun nanofibres containing different content of silver; (a) $0.01 \mathrm{wt} \%$, (b) $0.1 \mathrm{wt} \%$, (c) $1 \mathrm{wt} \%$ and (d) $5 \mathrm{wt} \%$. 


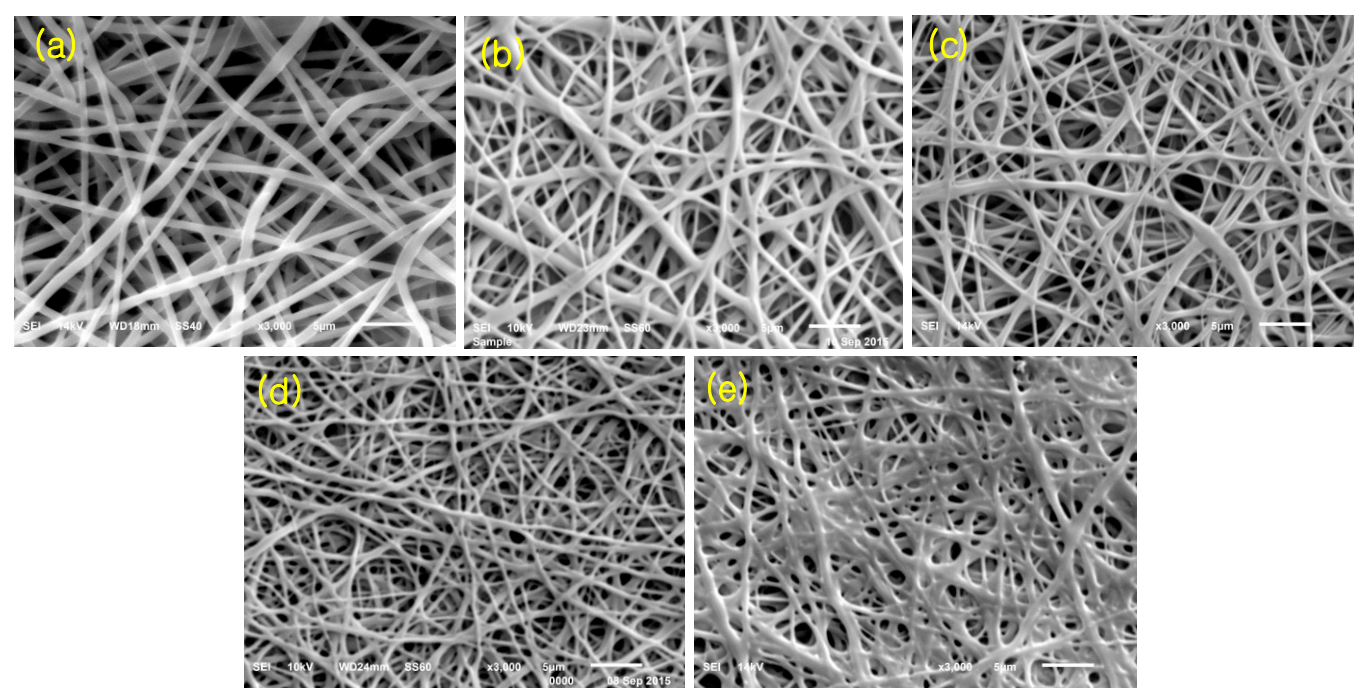

Fig. 4. SEM image of (a) pristine PU and (b) PU/Ag (0.01 wt\%), (c) PU/Ag (0.1 wt\%), (d) PU/Ag (1 wt \%) and (e) PU/Ag (5 wt\%). 

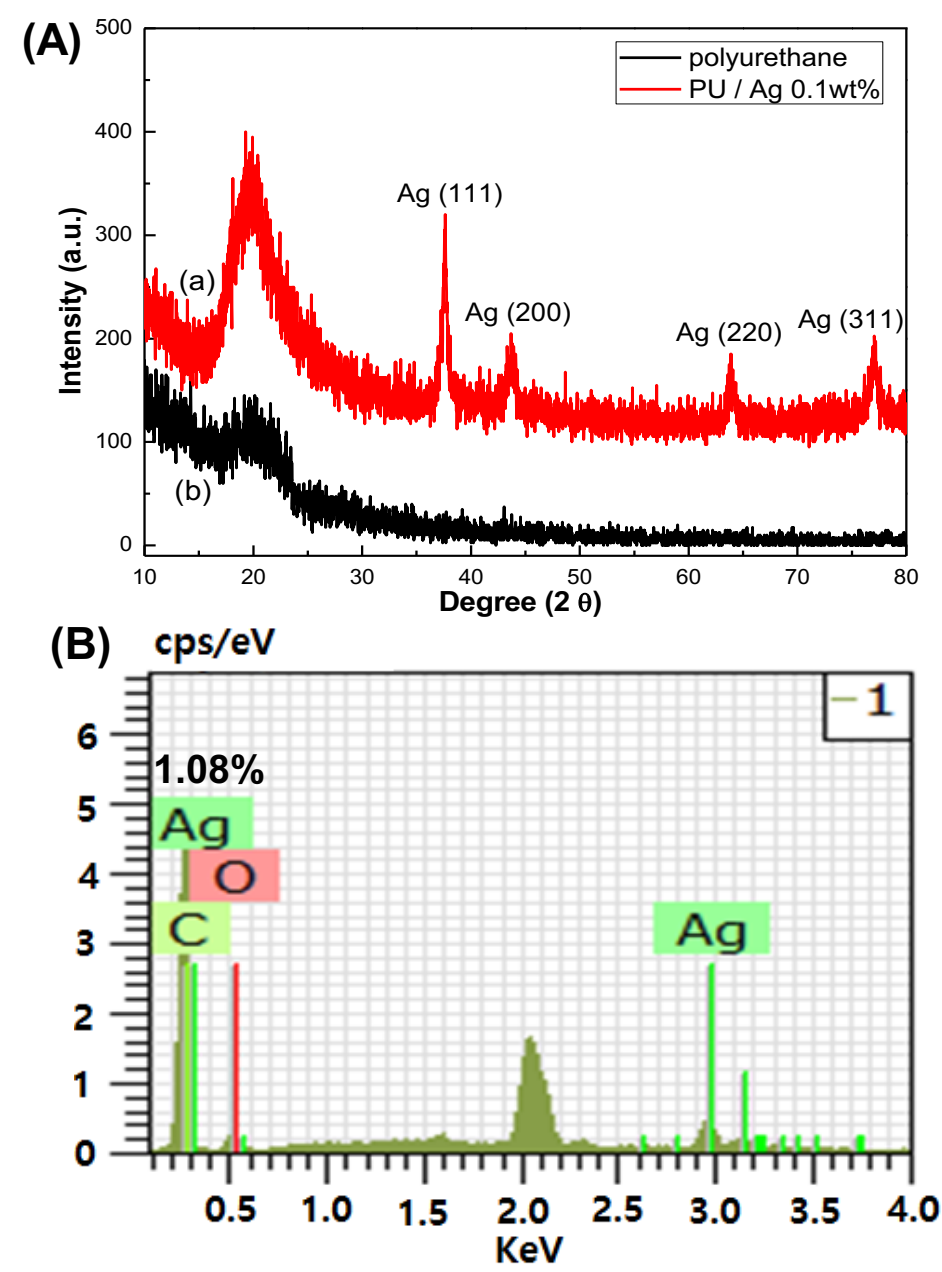

Fig. 5. (A) XRD patterns of a) PU/Ag nanofiber fabric with $0.1 \mathrm{wt} \%$ silver and (b) pristine PU, and (B) energy-dispersive spectroscopy (EDS) spectrum of PU/Ag Nanofiber fabrics. 


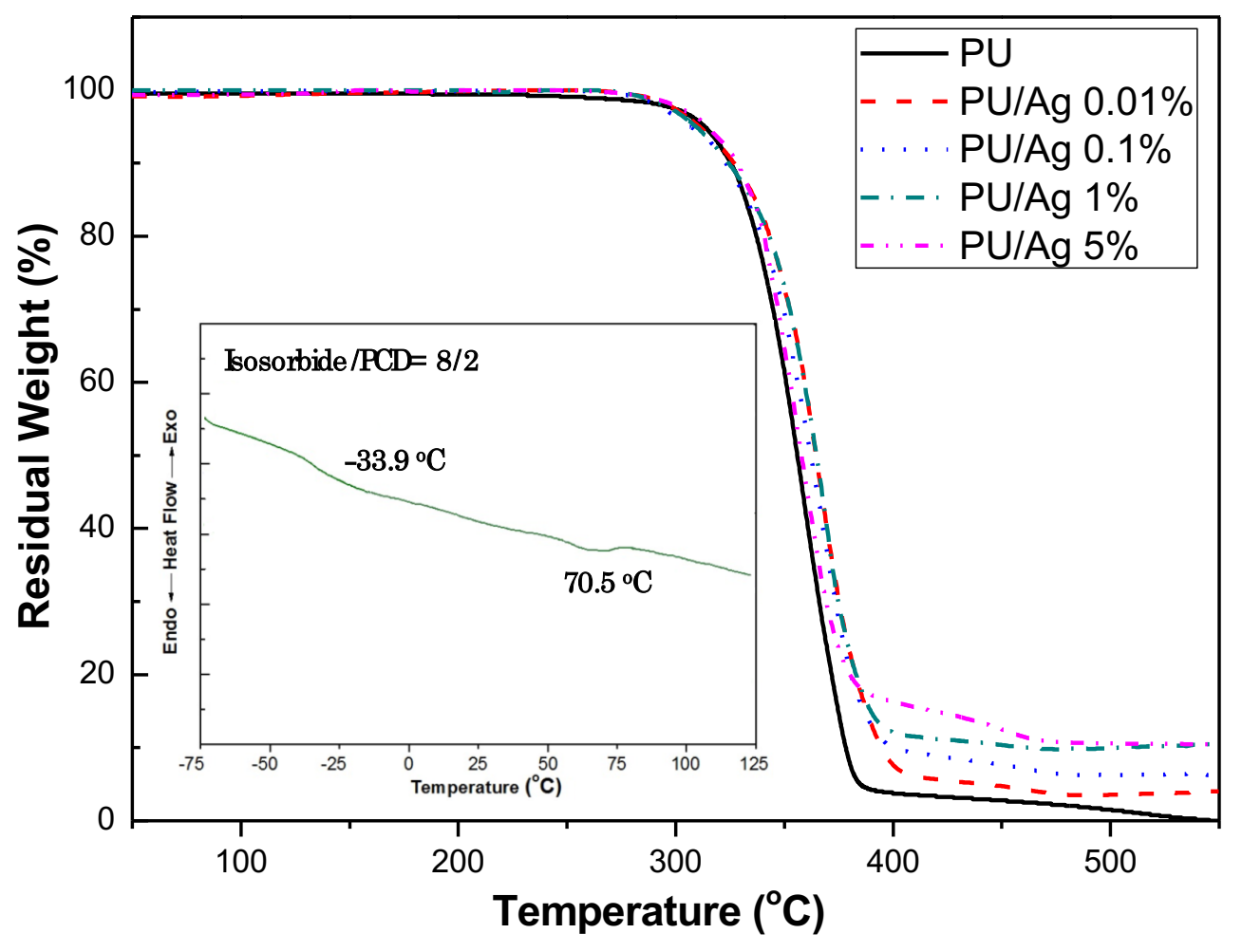

Fig. 6. TGA analysis of pristine PU and PU/Ag nanofiber fabrics. 

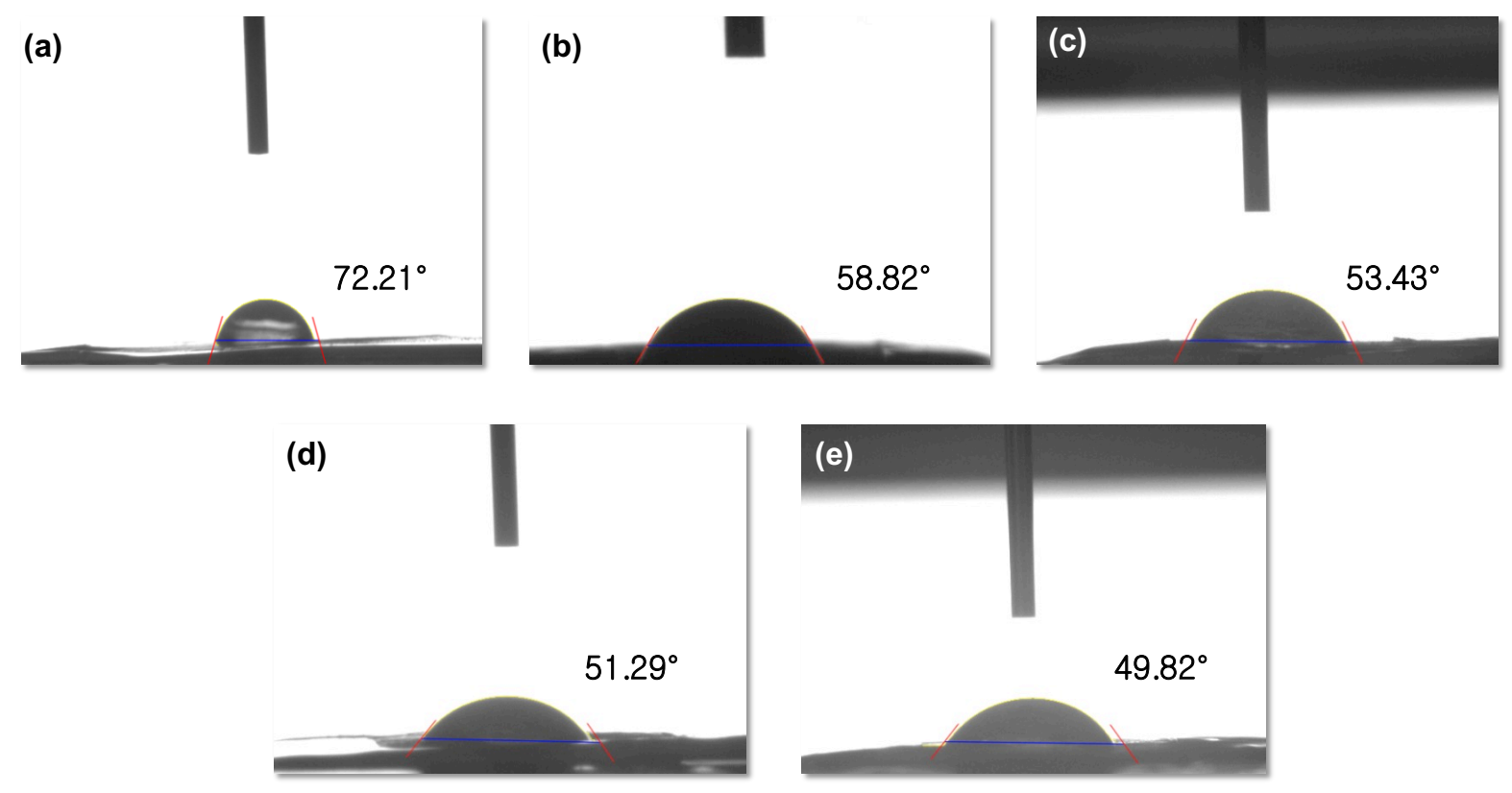

Fig. 7. Contact angle images of (a) pristine PU and (b) PU/Ag (0.01 wt\%), (c) PU/Ag (0.1 wt\%), (d) PU/Ag (1 wt\%) and (e) PU/Ag (5 wt\%). 

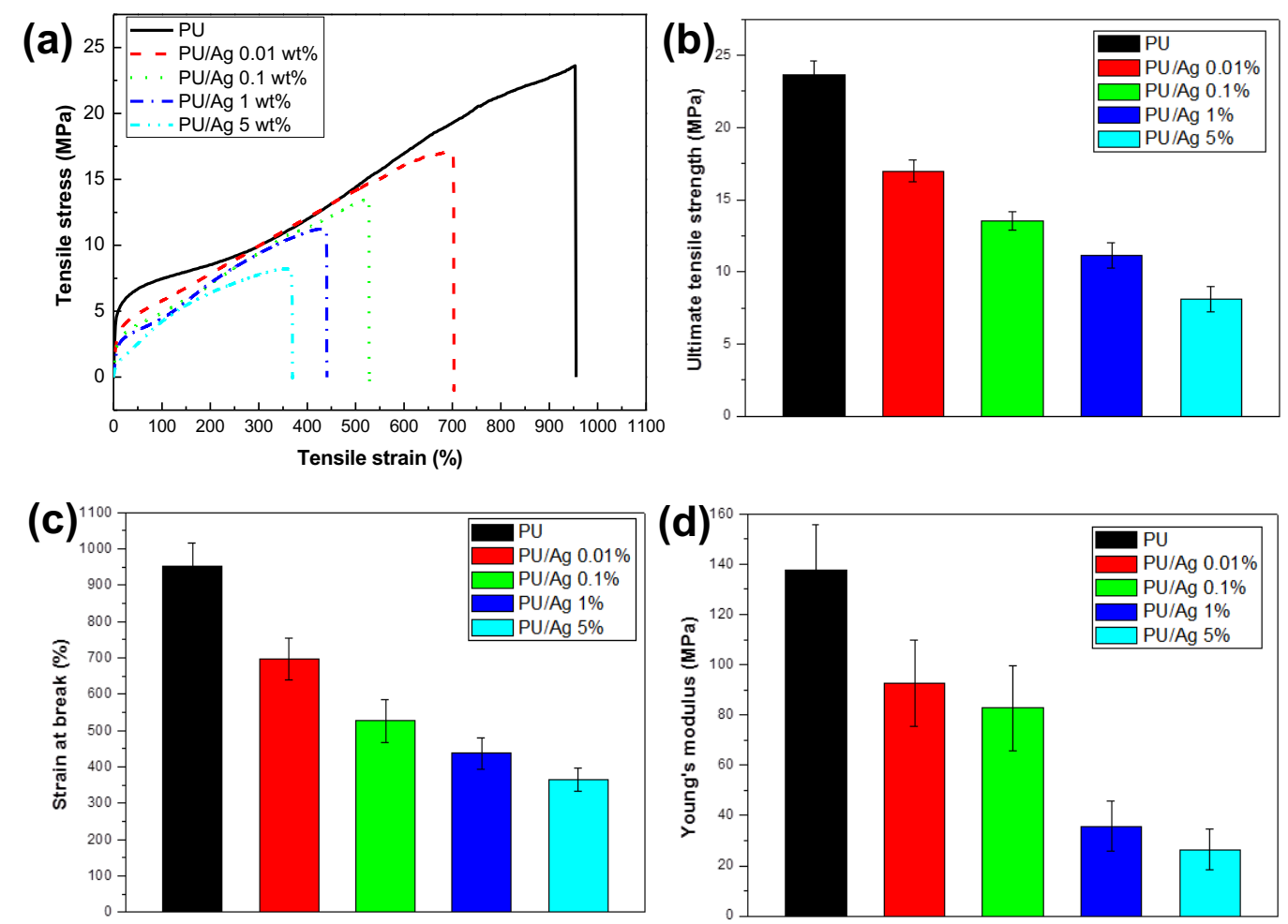

Fig. 8. Tensile strain vs tensile stress curves of thermoplastic PU/Ag nanofiber fabrics. 


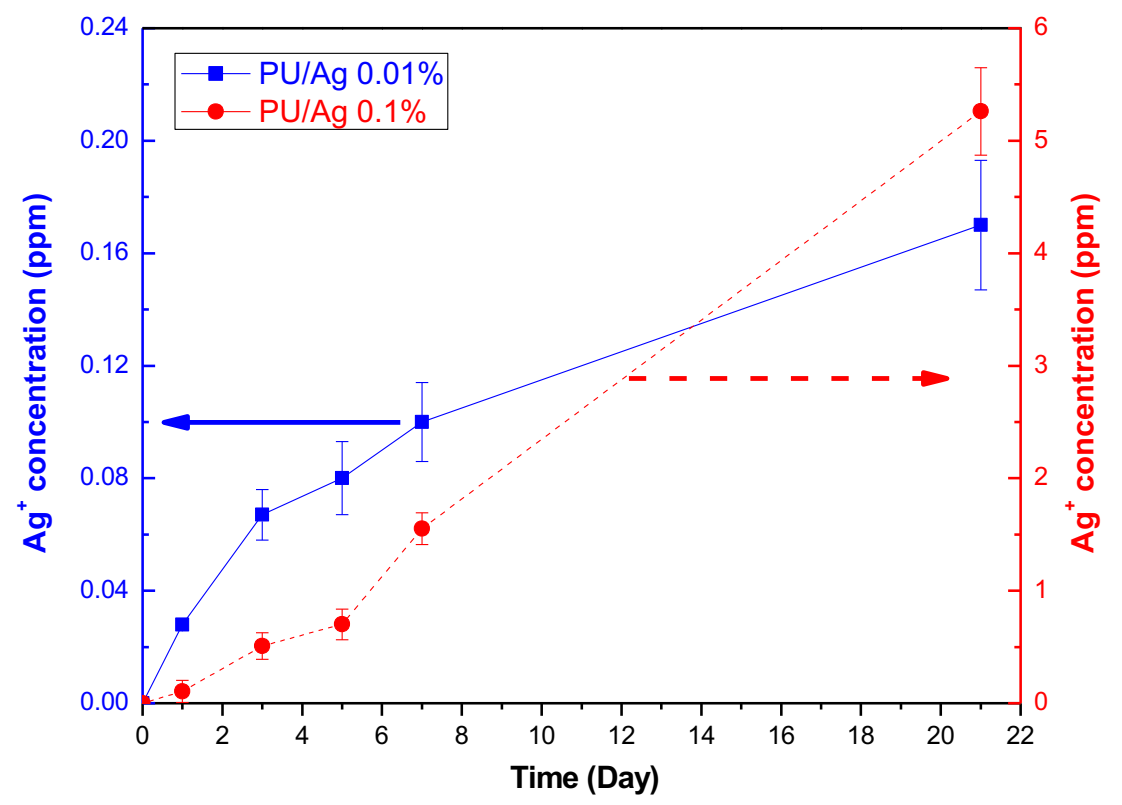

Fig. 9. Silver ion $\left(\mathrm{Ag}^{+}\right)$release after immersing sample in water.

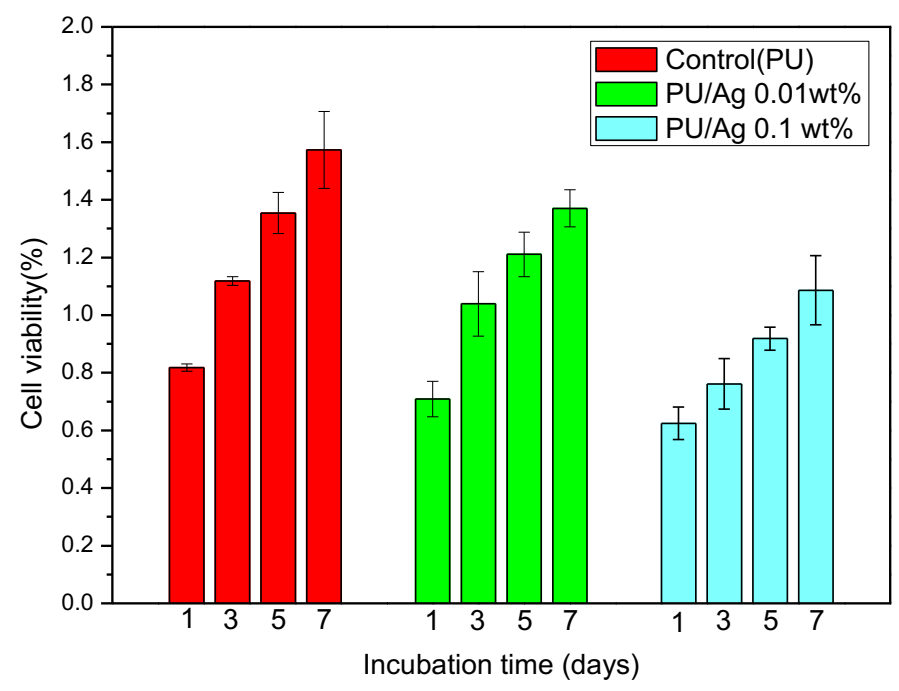


Fig. 10. The MTT cell viability of control cells were set $100 \%$, and viability relative to the control was expressed. 


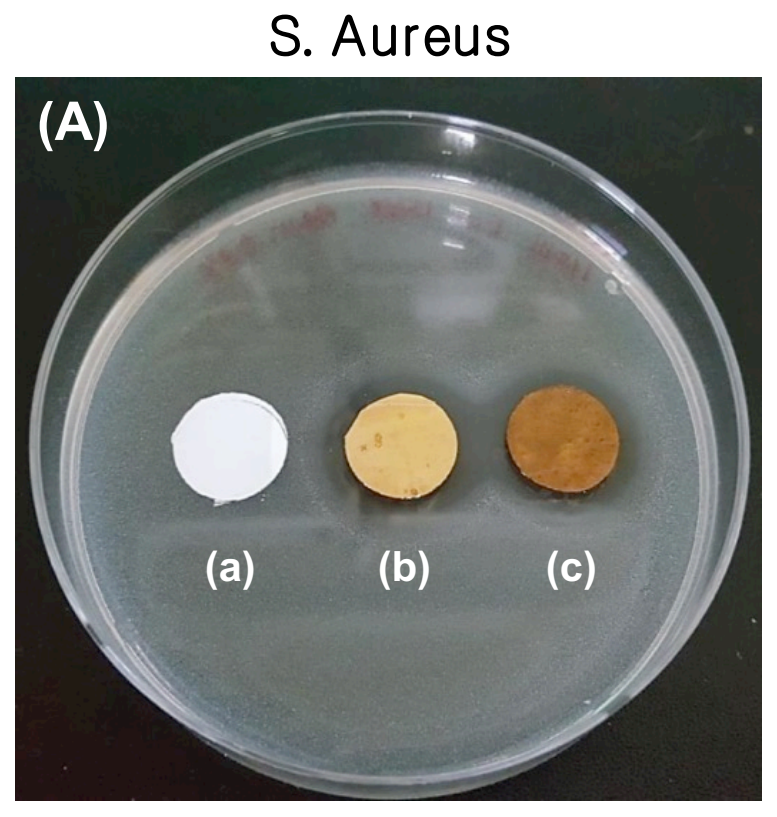

(a) polyurethane(nagative control)

(b) PU/Ag $0.01 \%-20.36 \mathrm{~mm}$

(c) PU/Ag $0.1 \%-20.47$ mm

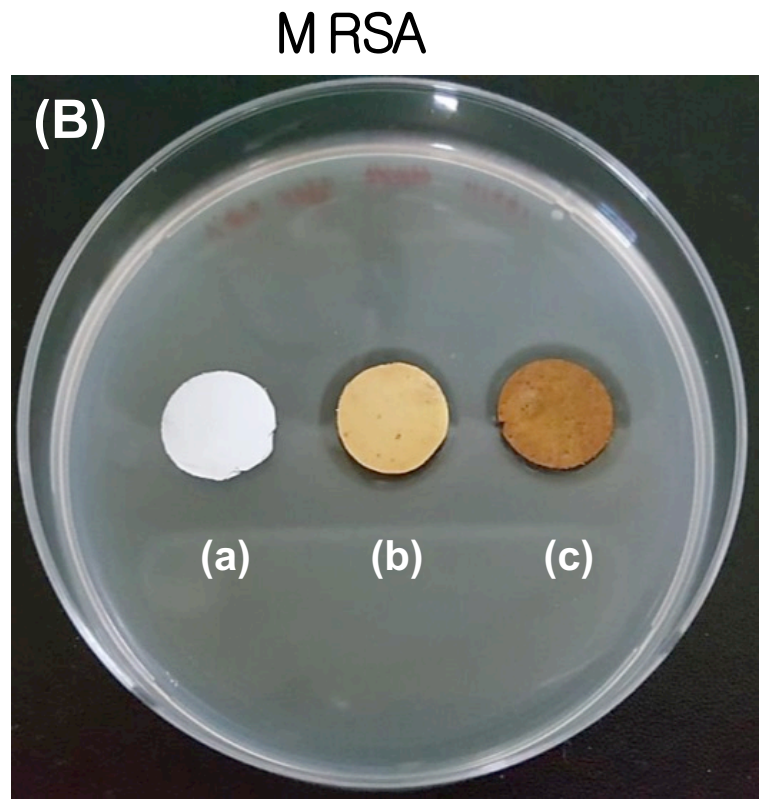

(a) polyurethane(nagative control)

(b) PU/Ag $0.01 \%-\mathbf{1 7 . 8 3} \mathbf{~ m m}$

(c) PU/Ag $0.1 \%-\mathbf{1 8 . 6 6} \mathbf{~ m m}$

Fig. 11. The plate morphology of (A) S. aureus and (B) MRSA cells exposed to (a) pristine PU, (b) PU/Ag (0.01 wt\%) and (c) PU/Ag (0.1 wt\%) nanofiber fabrics. 

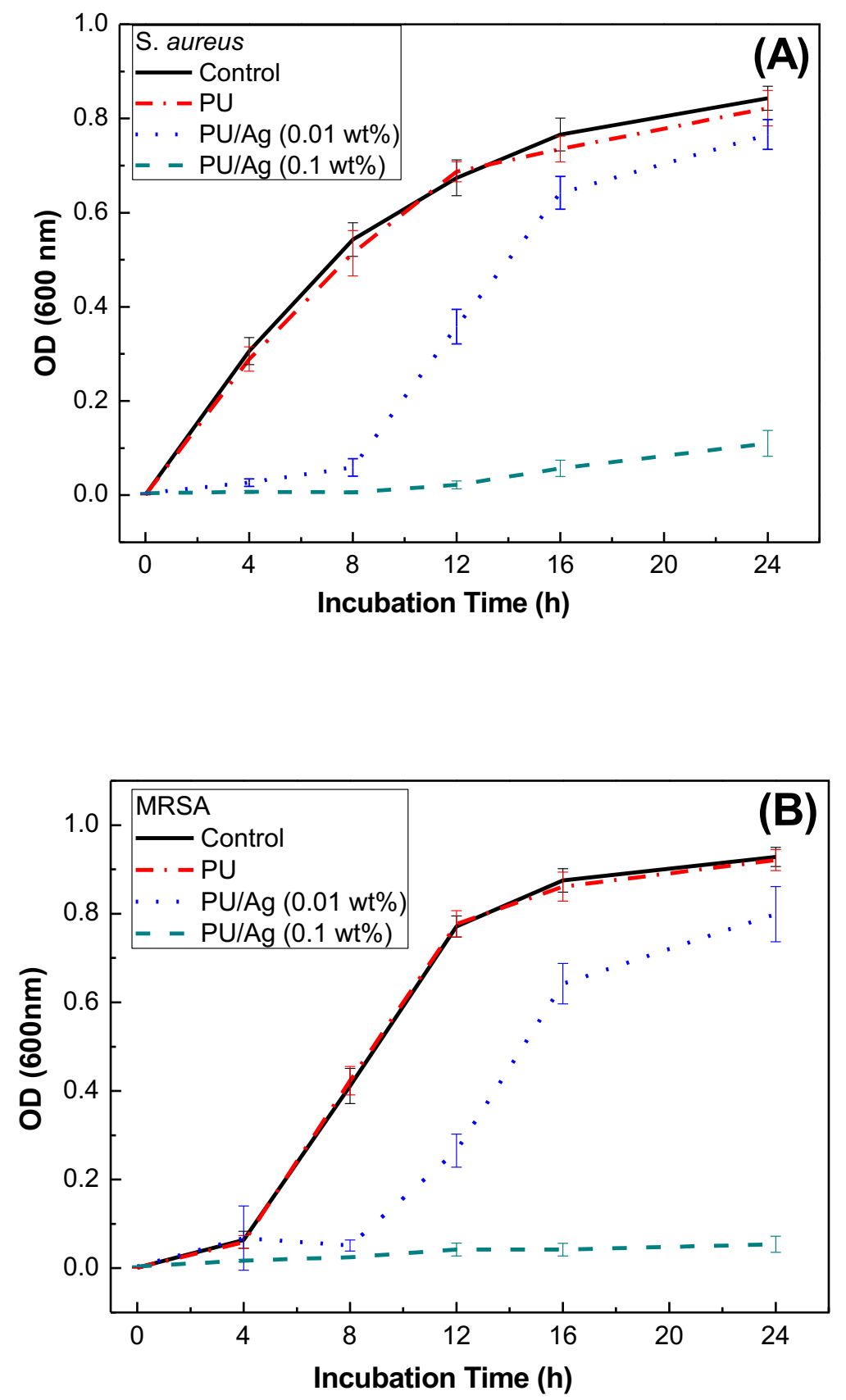

Fig. 12. Growth curve of (A) S. aureus and (B) MRSA cells exposed to no nothing medium, pristine PU, PU/Ag (0.01 wt $\%)$ and PU/Ag (0.1 wt\%) nanofiber fabrics. 